\title{
Inception innova en el modelado 3D aplicado al patrimonio cultural con un enfoque inclusivo
}

\begin{abstract}
INCEPTION es un proyecto europeo de I+D que propone innovaciones en la digitalización del patrimonio cultural a través de la reconstrucción 3D dinámica (a lo largo del tiempo) de objetos, entornos y edificios, desde un enfoque inclusivo (para cualquier usuario). Su objetivo es enriquecer aún más la identidad europea facilitando la comprensión del patrimonio cultural por medio de estos modelos 3D. El proyecto ha transcurrido entre los años 2015 y 2019 y ha contado con un equipo multidisciplinar compuesto por 14 entidades de 10 países de la UE. El centro tecnológico CARTIF ha participado como socio español.
\end{abstract}

Pedro Martín Lerones | Fundación CARTIF

Url de la contribución <www.iaph.es/revistaph/index.php/revistaph/article/view/4532>

El proyecto de I+D INCEPTION ${ }^{1}$ (Inclusive Cultural Heritage in Europe through 3D semantic modelling), transcurrido ente los años 2015 y 2019, ha permitido integrar tecnologías de digitalización y desarrollar herramientas informáticas para comprender mejor el extraordinario y variado patrimonio cultural europeo a través de modelos 3D enriquecidos semánticamente, es decir, gracias a copias virtuales que no sólo son pura información gráfica descontextualizada, sino que se complementan con aquella otra información necesaria tanto para el conocimiento generalista del ciudadano como para el profesional que demanda un análisis especializado. Cada uno de ellos hará uso del nivel de información que requiera, desde lo más básico, como fotografías, vídeos, paseos virtuales y publicaciones relacionadas, hasta otros más complejos, como apariencia cromática, elementos constructivos, catalogación y significancia del bien, tipos de materiales, propiedades, imágenes en diferentes bandas espectrales, georreferenciación, planos detallados, planes directores, informes de intervenciones, etc.

Coordinado por la Universidad de Ferrara (Italia), con un equipo multidisciplinar compuesto por 14 entidades de 10 países de la UE, INCEPTION presentó sus resultados finales en Zagreb (Croacia) en julio de 2019. Nueve demostradores (dos museos, tres iglesias, un palacio, un castillo, una excavación arqueológica y una casa histórica), que en conjunto cubren los principales rangos cronológicos, constructivos, arquitectónicos y estilísticos del patrimonio cultural europeo, han sido los campos de pruebas sobre los que validarlos. Estos resultados son accesibles en la llamada INCEPTION-Platform², una plataforma web que actúa como repositorio de los modelos $3 \mathrm{D}$ de esos nueve demostradores y toda la información complementaria relacionada con ellos. Las funcionalidades de la plataforma fueron auspiciadas por un panel internacional de expertos de organizaciones europeas de reconocido prestigio, que han actuado en el proyecto en calidad de observadores externos.

Castilla y León es la comunidad autónoma española que atesora mayor número de bienes de interés cultural. Dentro de ella, CARTIF es el único centro tecnológico con dedicación específica a la investigación aplicada al patrimonio cultural desde hace casi veinte años, contando con una dilatada experiencia en digitalización y modelado 3D, motivos que le han llevado a ser el socio español de INCEPTION. CARTIF ha trabajado sobre el castillo de Torrelobatón (Valladolid) como demostrador representativo de la arquitectura de fortificación, y ha contado con el respaldo de la Consejería de Cultura y Turismo de la Junta de Castilla y León, y del Instituto del Patrimonio Cultural Español (dependiente del Ministerio de Cultura y Deporte) como observadores externos por parte de nuestro país. El interés común a todos ellos ha sido evaluar la particularización de la filosofía BIM (Building Information Modeling) a los inmuebles de interés cultural, puesto que está orientada a nuevas cons- 
trucciones. La singularidad y sensibilidad que exige el patrimonio cultural requiere de adaptaciones tecnológicas y metodológicas que han originado el concepto de Heritage BIM (HBIM o H-BIM).

Representar digitalmente la apariencia de un inmueble de interés cultural a través de técnicas de modelado 3D no resuelve el problema de la integración y manejo de la información multidisciplinar sobre el mismo. Solucionarlo aumentaría enormemente la eficiencia y la eficacia de los procesos de documentación, protección, conservación, restauración y difusión del patrimonio europeo, y este ha sido el telón de fondo de INCEPTION.

De hecho, desde julio de 2019 la Directiva europea 2014/24/UE impone el denominado "BIM nivel 2" para proyectos de contratación pública, y esto también afecta al patrimonio cultural. El nivel 2 implica que el flujo de trabajo ha de ser colaborativo, y para que esto sea así, todos los datos, la información y la documentación relacionados con el inmueble de que se trate deben estar en formato electrónico y han de gestionarse en un entorno digital común. La plataforma INCEPTION es el arquetipo de cómo deben ser este tipo de entornos.

CARTIF ha modelado el castillo de Torrelobatón a partir de la nube de puntos obtenida de su digitalización, transcribiéndolo al formato estándar IFC (Industry Foundation Classes), para que sea visible y manipulable en cualquier software BIM. El modelado 3D a partir de nubes de puntos es un proceso manual, tedioso, cuyos resultados dependen enormemente de la pericia de la persona encargada. Por estos motivos se ha creado una novedosa metodología de delineación 3D que tiene en cuenta el proceso constructivo original en la medida que se conoce, permitiendo que los elementos arquitectónicos que conforman el castillo sean entidades 3D universalmente reconocibles mediante su vinculación al Getty-AAT (Tesauro de Arte y Arquitectura desarrollado por el Getty Research Institute de EE.UU.).

El proceso de delineación ha sido acelerado mediante una herramienta informática desarrollada al efecto (3DASH tool) ${ }^{3}$, que permite extraer automáticamente y con precisión milimétrica características geométricas

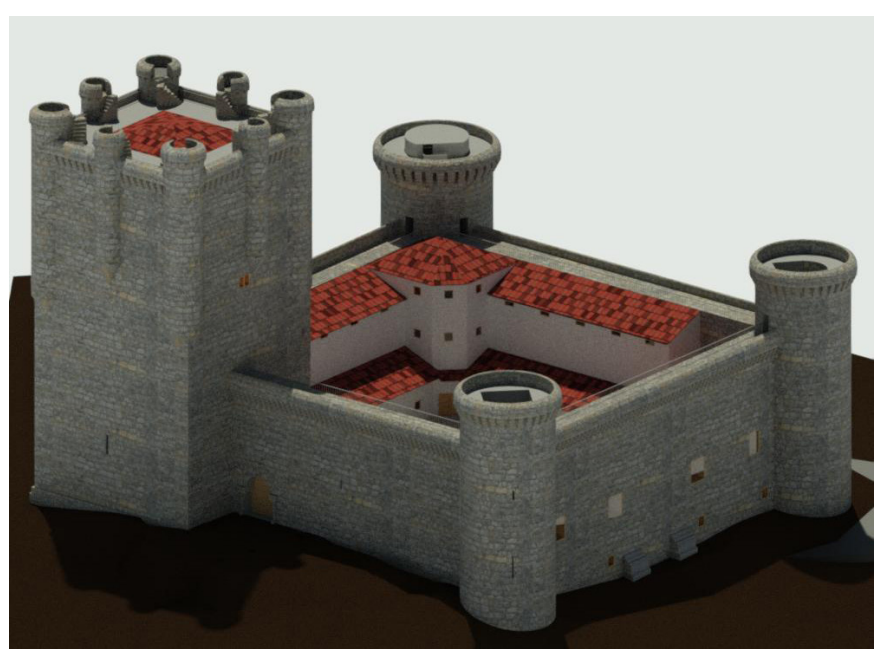

Modelo 3D en formato IFC realizado a partir de la nube de puntos del castillo de Torrelobatón (Valladolid)

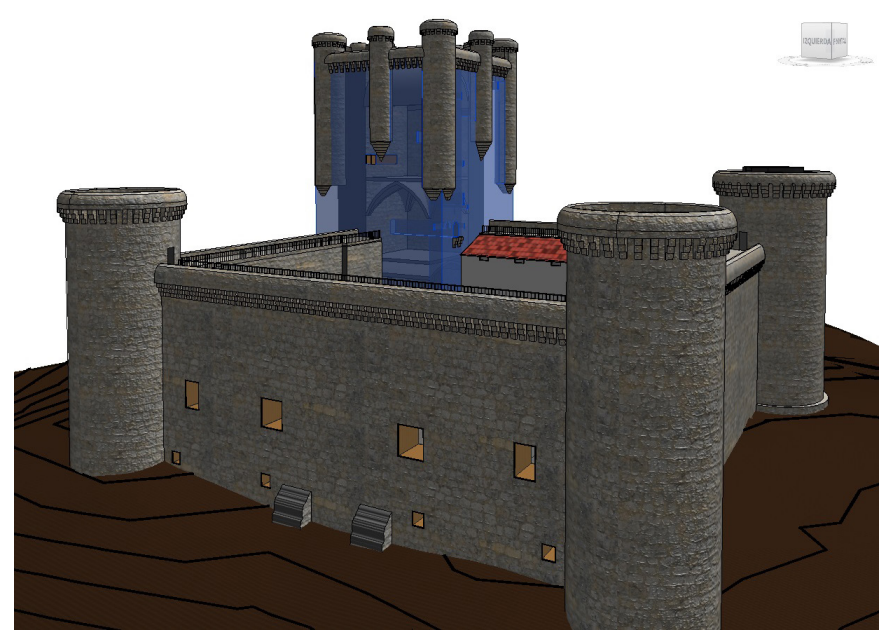

Vinculación del elemento "torre del homenaje" con el término "Keep" del GettyAAT

básicas a partir de la nube de puntos, como planos, cilindros, conos, esferas y toroides. Con ello se asegura también que el modelo tiene una calidad adecuada, reduciendo la dependencia indicada respecto de la persona que realiza la delineación.

Para poder combinar en BIM informaciones 2D (imágenes de diferentes tipos y resoluciones) con la nube de puntos, CARTIF ha establecido además una técnica soportada por otro desarrollo informático específico (LOKI tool) ${ }^{4}$ que permite que imágenes fotográficas 


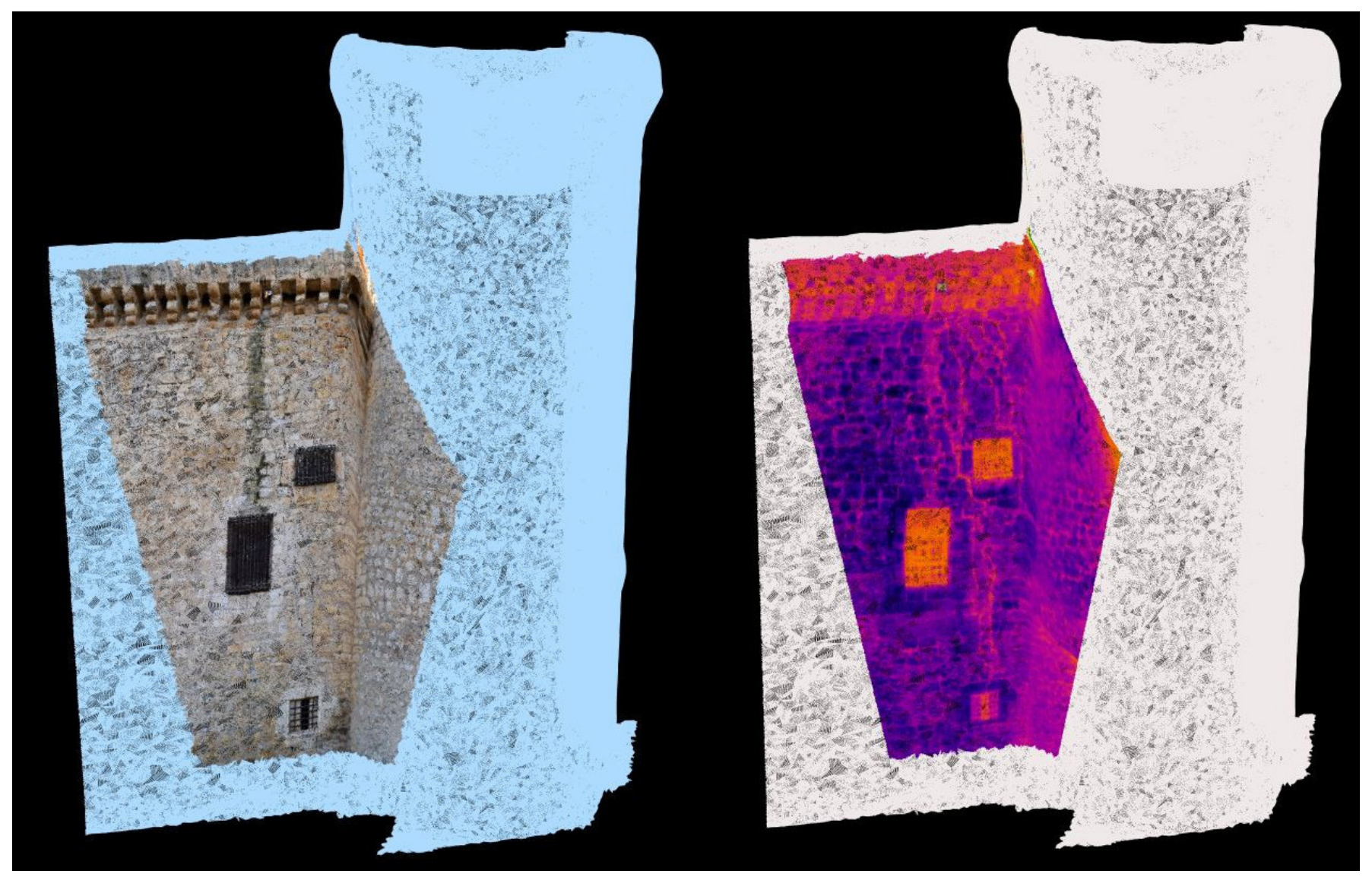

Superposición sobre la nube de puntos de una imagen fotográfica de alta resolución (izquierda) y de una imagen termográfica (derecha)

de alta resolución, imágenes multiespectrales y termografías, se superpongan a esa nube, visualizándose a voluntad unas u otras para ser utilizadas como plantiIlas 3D que permitan delinear los aspectos que cada una permite resaltar para ser incluidos en BIM. De esta forma se hacen compatibles las informaciones de los equipos de captación de imágenes y los de digitalización 3D, aspecto muy útil para planificar y evaluar intervenciones.

Aunque no ha sido un objetivo específico de INCEPTION, a través de plataformas como la desarrollada, incluso podrían vincularse aspectos inmateriales (tradiciones orales registradas como sonido, danzas o procesiones como videograbaciones, entre otros aspectos), integrándose lo tangible con lo intangible sobre un inmueble digitalizado.

INCEPTION demuestra que el patrimonio cultural es patrimonio de todos y para todos y que la tecnología ha llegado hasta él para quedarse, y no ya sólo para hacerlo accesible y comprensible al ciudadano, sino para dotar de armas del siglo XXI a todos aquellos profesionales que con su esfuerzo hacen que dure tantos o más años que lo que lleva enseñándonos por qué somos como somos, qué historias debemos repetir y cuáles no en una Europa de multiculturalidad creciente.

\section{NOTAS}

1. Más información en https://www.inception-project.eu

2. http://www.inceptionhbim.eu/Platform

3. https://www.youtube.com/watch?v=QpYiPX71Hms

4. https://www.youtube.com/watch?v=gtjDbyV-tLs 